\title{
OS MOVIMENTOS SOCIAIS COMO ALTERNATIVA PARA A EFETIVAÇÃO DA PARTICIPAÇÃO CIDADÃ NO ESTADO DEMOCRÁTICO DE DIREITO
}

\section{SOCIAL MOVEMENTS AS ALTERNATIVE FOR THE EFFECTIVATION OF CITIZEN PARTICIPATION IN THE DEMOCRATIC RULE OF LAW}

\author{
Elisaide Trevisam* \\ Julio Trevisam Braga**
}

\section{RESUMO}

O presente artigo traz uma reflexão sobre o papel dos movimentos sociais para o impulsionamento da participação dos cidadãos dentro do Estado Democrático de Direito, desde o contexto histórico das consequências culturais, políticas e econômicas vivenciadas a partir da década de 70, até os dias atuais. Diante do histórico desses movimentos, esta reflexão tem como proposta propiciar um debate sobre as possíveis alternativas de participação cidadã na atualidade social e política.

Palavras-Chave: Movimentos sociais; Participação cidadã; Estado Democrático de Direito; Teorias econômicas.

\begin{abstract}
This article presents a reflection on the role of social movements in the promotion of citizen participation within the Democratic Rule of Law, out the historical context of the cultural, political and economic consequences lived from the 1970's, up to the present day. Facing these movements historics, this reflection proposes to promote a debate about the possible alternatives of citizen participation on social and political actuality.
\end{abstract}

Keywords: Social Movements; Citizen participation; Democratic rule of law; Economic theories.

\footnotetext{
* Doutora em Filosofia do Direito pela Pontifícia Universidade Católica de São Paulo - PUC-SP, São Pualo, (Brasil). Mestre em Direitos Humanos. E-mail: elis.trevi@hotmail.it

** Doutorando e Mestre em História Social pela Pontifícia Universidade Católica de São Paulo - PUC-SP.

E-mail: julio.t.braga@gmail.com
} 


\section{INTRODUÇÃO}

No contexto de mudanças de paradigmas que se inicia nos anos de 1970, aproximadamente, tanto o pensamento político adquire novas nuances, configurando um perfil cada vez mais afastado dos ideais do Estado de bem-estar social, quanto, ao seu redor, vinha se desenvolvendo durante as décadas posteriores um déficit democrático cada vez mais marcante entre as sociedades ocidentais.

Se até a década de 1970, dada às consequências econômicas e sociais do pós-guerra, as práticas reformistas se encontravam estruturadas fazendo valer a diminuição das desigualdades no interior do Estado, através da oferta de subsídios governamentais às populações mais carentes ou da implantação de tributos e impostos progressivos, após esse período, a presença do Estado no desenvolvimento econômico passaria gradativamente a ser vista com maus olhos.

Nesse novo contexto, o papel a ser atribuído ao Estado seria o de mero intermediador, sem que a sua interferência pudesse comprometer o desenvolvimento econômico.

Em contrapartida, após a queda do Muro de Berlim, as consequências da desestabilização financeira irão denunciar que o protagonismo das especulações do setor financeiro na vida econômica do Estado estava, mais uma vez, levando as sociedades ocidentais ao colapso, contribuindo para que, entre outros, as filas do desemprego aumentasse a cada dia.

Desse modo, justificando a necessidade de se pensar a atual conjuntura do mundo em que vivemos, esse artigo busca refletir brevemente sobre como o embate entre o crescimento econômico e a desigualdade irá compor as diferentes teorias econômicas e, por outro lado, como as críticas ao modelo capitalista de especulação financeira estiveram alinhadas, historicamente, a uma crescente insatisfação popular frente à representação oferecida pelas classes políticas na defesa aos direitos abrigados pelo Estado Democrático de Direito e que estarão presentes, portanto, entre os diferentes movimentos sociais despontados no decorrer dessas décadas. 
Para alcançar uma resposta satisfatória da presente reflexão, a metodologia usada foi de cunho dialético e bibliográfico, pretendendo atingir o escopo sugerido.

\section{O EMBATE ENTRE CRESCIMENTO ECONÔMICO E DESIGUALDADE}

No imediatismo do pós- $2^{\text {a }}$ Guerra Mundial, mas particularmente até a década de 1970, o ocidente esteve envolvido na busca de fazer diminuir as desigualdades no interior do Estado, a partir de práticas reformistas de oferta de subsídios governamentais às populações mais empobrecidas, implantação de tributos e impostos progressivos, articuladas a fim de garantir o acesso a serviços por parte de uma população que saía, a pouco, dos infortúnios que o resultado de uma guerra, a nível mundial, pode oferecer.

Ainda que as especificidades de cada contexto configurem tonalidades diferentes entre os diferentes Estados, para Tony Judt (2011, p. 25), cada país, a seu modo, esteve afetado pela presença da desigualdade e, ao mesmo tempo, intolerante ao seu desequilíbrio crescente, dando voz para que iniciativas públicas fossem instauradas para evitar e compensar a carência da iniciativa privada.

Sem exceção, vencedores e derrotados na Segunda Guerra Mundial comprometeram não só o país, a economia e cada um dos cidadãos nas atividades bélicas; também mobilizaram o Estado para este propósito de um modo que teria sido inconcebível trinta anos antes. Independentemente dos matizes ideológicos, os países combatentes mobilizaram, regulamentaram, dirigiram, planejaram e administraram todos os aspectos da vida (JUDT, 2011, p. 60).

As estratégias para a reconstrução dos Estado no pós-guerra acolheram medidas estruturadas no planejamento e no controle a curto prazo: uma vez que a experiência da livre iniciativa do mercado - articulada ao empreendimento bélico - tinha envolvido os países combatentes numa conjuntura de desestabilização econômica e social, a alternativa para o período se direcionou ao Estado para que este assumisse a responsabilidade de trazer aos países o desenvolvimento equilibrado para o interesse público.

Desse modo, até a década de 1970, ao lado do horizonte idealizado por iniciativas estabelecidas em prol do equilíbrio econômico e social, o espectro do desenvolvimento econômico toma as rédeas ao circular a ideia de que o incentivo ao crescimento da riqueza no 
interior do Estado permitiria, consequentemente, que seus benefícios pudessem ser alcançados, de modo geral, por toda a população.

$\mathrm{Na}$ perspectiva dos teóricos economicistas, avessos à ideia de uma intervenção externa extrapolada sobre o desenvolvimento econômico, até aquele momento não se via a possibilidade de um risco grave às operações de mercado.

O mercado tinha o seu lugar, o Estado garantia um papel central na vida das pessoas, e os serviços sociais tinham prioridade sobre outras despesas do governo - exceto, parcialmente, no caso americano, no qual os gastos militares continuavam crescendo mais (JUDT, 2011, p. 67).

Considerando que o mercado, por si só, não era capaz de sustentar um resultado positivo para o equilíbrio do "bem-estar", o exemplo do aumento dos impostos era visto, naquele momento, com bons olhos.

A medida de impor maiores taxas sobre o imposto de renda progressivo andava de acordo com o consenso de retirar o excesso dos recursos de setores privilegiados e improdutivos, para então ser transferido e reutilizado entre as populações mais carentes.

Entretanto, se por quase três décadas ao Estado era confiado a tarefa de priorizar o desenvolvimento com vistas a atender a demanda da coletividade, segundo os críticos dessa postura, os custos para a implementação dos benefícios à população se contorciam entre a ineficiência econômica, a inovação insuficiente, o empreendedorismo sufocado, a dívida pública e a decadência da iniciativa privada (JUDT, 2011, p. 75).

A proposição para uma mudança de paradigma tornava-se cada vez mais inevitável para os críticos conservadores, à medida que a presença do Estado enfraquecia gradativamente a iniciativa privada.

Assim, se para o novo paradigma o governo se torna o problema e a sociedade, vista até então como um coletivo, dá lugar à soma de indivíduos com interesses próprios, o papel a ser atribuído ao Estado retorna ao de mero facilitador.

Portanto, a função do político será o de "determinar o melhor para o indivíduo, e depois fornecer as condições para ele alcançar seu objetivo com o mínimo e interferência" (JUDT, 2011, pp. 96-97). 
De um lado, essa nova postura irá assumir o estímulo à privatização de espaços, recursos e serviços públicos, uma vez que muitas das operações sob os cuidados estatais atuavam, naquele momento, em prejuízo.

A questão polêmica, por outro lado, foi a de que se o Estado cedeu progressivamente o seu protagonismo à iniciativa privada, ao mesmo tempo pode-se dizer que as funções do Estado de bem-estar social foram discretamente desmontadas "para beneficiar um punhado de empresários e acionistas" (JUDT, 2011, p. 112).

Nesse ponto, como outras das críticas sobre o modelo reformista, mesmo que o crescimento econômico afetasse todas as categorias no interior de um Estado, logo o privilégio de exploração de sua riqueza total terminaria por privilegiar, desproporcionalmente, uma minoria posicionada para tanto. Um dos resultados que podem ser visualizados a partir dessa nova etapa é um déficit democrático cada vez mais marcante nas sociedades ocidentais.

Um dos fatores que talvez mais contribuíram para a descrença popular na tutela do Estado foi que, a partir de 1970, aproximadamente, o mal da desigualdade passou a representar um horizonte cada vez mais próximo da realidade.

Ao lado do crescimento da margem de desempregados, o aumento dos impostos e das previdências gerado pelo curso inflacionário iria incrementar ainda mais o cenário das insatisfações.

Nesse sentido, na mesma velocidade em que a economia passaria a crescer desproporcionalmente, dado o protagonismo cada vez maior das especulações do setor financeiro privado - e que assim iria seguir até o início da década de 1990 -, o aumento das rendas entre a classe trabalhadora habituada aos benefícios da "Era de Ouro" se estagnariam progressivamente.

E, portanto, para Eric J. Hobsbawm, o que, de fato, iria acontecer nos períodos marcados pela crise, nomeados a partir de então como as "Décadas de Crise", não dizia respeito a ineficiência de crescimento do modelo capitalista - porque este estava indo muito bem, obrigado -, mas ao descontrole sobre as operações veiculadas pelo seu sistema (HOBSBAWM, 1995, p. 398). 
A queda do Muro de Berlim, em 1989, que iria legitimar o colapso dos regimes comunistas, ofereceu a alguns dos comentaristas da época o elemento essencial para o discurso de que aquele fato histórico representava por si só o fim da História.

A partir desse momento, o capitalismo liberal tomaria os rumos do mundo e o impulsionaria para frente, unindo-o "no rumo de um futuro marcado pela paz, pela democracia e pelos mercados livres", ideia que depois de vinte anos, para Judt, com a irrupção da crise financeira de 2008, não passaria de um simples engano (JUDT, 2011, p. 131).

Nessa perspectiva, com o colapso dos regimes socialistas ou declaradamente comunistas, igualmente o escândalo das posturas ditatoriais praticadas entre as diferentes experiências do ideal socialista e o consequente descrédito frente ao seu discurso terminaram, pois, por provocar a desmobilização da esquerda política no ocidente.

Para a esquerda [...] a ausência de uma narrativa historicamente sustentada criava um vácuo. Só restava a política: do interesse, da inveja, da reeleição. Sem idealismo, a política se reduz a uma forma de contabilidade social, de administração cotidiana de homens e coisas. Os conservadores também conseguem lidar bem com isso. Mas, para a esquerda, é uma catástrofe (JUDT, 2011, 135)

A afirmação de que a esquerda tenha se esvaziado de seu idealismo político, devido muito ao constrangimento com a postura ditatorial dos regimes socialistas, encontrará seu eco na crescente insatisfação popular frente à classe política pelo seu papel realizado - ou, no caso, não realizado - na defesa da coletividade contra a submissão do Estado à vasta margem da especulação financeira nacional e internacional e o peso do protagonismo do livre mercado sem limites sobre a garantia de direitos à população.

O resgate da dívida de bancos e instituições financeiras pelo banco central americano (o FED), e que até 2008 eram considerados inquebrantáveis, além de embocar numa crise sem precedentes - talvez comparável, em certa medida, apenas com a crise de 1929 -, mostrava ao mundo que a presença do Estado não tinha desaparecido totalmente como queriam mostrar as leituras catastróficas dos que atacaram a guinada liberal do livre-mercado, mas, por outro lado, a situação se mostrava bem pior: além de fazer despontar a sua presença, ao risco do colapso nacional e internacional muitos países passaram a onerar os cofres públicos na busca de salvar as instituições financeiras falidas. 
As consequências da desestabilização financeira sacrificada em prol de retomar o eixo das transações, as quais se tinham direcionado na aposta do maior lucro, inseriu forçosamente numerosas populações nas filas do desemprego ${ }^{1}$.

Atualmente, desde 2008, no mundo inteiro ocorreram mobilizações numerosas em protesto contra a especulação financeira internacional e em denúncia das classes políticas vigentes, aliadas à prática da governança pelo lucro e em ofensa aos ideais do Estado Democrático de Direito.

A partir de 2008, movimentos sociais recentes como a Primavera Árabe, a Revolução das Panelas, na Islândia, os Indignados, na Espanha, o Occupy Wall Street, nos EUA, e as Jornadas de Junho de 2013, no Brasil, entre outros tantos, tomaram as ruas, evidenciando um importante período de ebulição política, econômica, social e cultural, propondo um ativismo baseado num novo modelo de participação política.

Desse modo, se assumimos o consenso de que a ideologia da esquerda política, nos moldes tradicionais da democracia representativa, tenha perdido grande parte de seu charme revolucionário, de que modelo de participação política esses movimentos estão falando?

\section{OS MOVIMENTOS SOCIAIS NA BUSCA POR UM "NOVO MODO DE FAZER POLÍTICA"}

Bem antes que estes movimentos gerados em torno da crise financeira de 2008 despontassem com a proposta de romper com status quo e implementar um novo modo de fazer política, movimentos como as ocorridos no Maio de 1968 em diversas localidades do mundo e o estabelecimento do Fórum Social Mundial, em 2001, forneceram um cenário de experimentação de princípios que, em seus diferentes contextos, circulava o incentivo à quebra de paradigmas e à criação de alternativas políticas e culturais aos modelos tradicionais de organização da sociedade.

Em relação aos eventos que compuseram a onda de protestos e revoltas em maio de 1968, por todo o mundo, podemos dizer, nomeadamente, que se encontravam interligados a uma vasta gama de rupturas, inscritas, por sua vez, num ativismo antiautoritário de críticas às

\footnotetext{
${ }^{1}$ No dia 28 de janeiro de 2009, a Organização Internacional do Trabalho (OIT) divulgou, no relatório das Tendências Mundiais de Emprego, os resultados da previsão de que a escala de desemprego provocado pela crise financeira de 2008, no mundo, poderia alcançar o número de 50 milhões de novos desempregados. Para a íntegra do relatório, acessar: <http://www.oitbrasil.org.br/sites/default/files/topic/employment/doc/get_2009_61.pdf>.
} 
autoridades estatais e às autoridades científicas das universidades, às instituições como a família, os partidos e ao sistema político como um todo.

O epicentro das manifestações surgiu de dentro das universidades de Nanterre e Sorbonne, na França, num momento de pura desconfiança em relação à toda uma tipologia de autoridades e hierarquias, entre as mais variadas instituições.

Essa desconfiança daria início a uma série de contestações que contornavam questões relacionadas à recusa do caráter classista na universidade, às denúncias de uma falsa neutralidade e objetividade nos campos do saber - principalmente da economia -, uma crítica à ligação de professores à política do governo e, inclusive, ao questionamento sobre que destino teriam os diplomados na divisão capitalista do trabalho, denunciado pela escassez de possibilidade de empregos qualificados (THIOLLENT, 1998, p. 70).

Ao lado destas questões, logo outros questionamentos passariam a ser levantados dizendo respeito a todo conteúdo da sociedade e da vida em geral.

A crítica ao conhecimento ensinado nas universidades, elaborado até aquele momento como meio para a justificação do status quo deu margem para que um aparato de contestação no âmbito global, aliado a outros setores da sociedade, fosse incentivado e mobilizado em todo o mundo, trazendo à tona a reivindicação de objetivos políticos, "tais como democratização, defesa das liberdades individuais ou coletivas", com o fortalecimento do movimento feminista pela igualdade das mulheres, "denúncia contra as guerras etc." (THIOLLENT, 1998, p. 65).

Nos âmbitos do ensino e da pesquisa, a influência das experiências norte-americanas no ensino francês estimulou o movimento estudantil a se levantar contra a entrada nas universidades de um conhecimento de "teorias tranquilizantes", promotoras da aceitação de uma "realidade caótica e desigual", levando o movimento a uma crescente "crítica dos fundamentos da economia e de seus compromissos com os interesses de classe" (THIOLLENT, 1998, p. 81).

Logo que as mobilizações estudantis começaram a chamar mais atenção aos olhos do poder público e da população, a partir do dia 10 de maio, o movimento operário organizou uma paralisação totalizando o número de dez milhões de manifestantes nas ruas, junto dos estudantes. 
Entretanto, depois de passados dezessete dias de paralisação dos trabalhadores, houve um fortalecimento das negociações entre o governo, os sindicatos de trabalhadores e de empresários, freando em grande parte a greve dos trabalhadores e, consequentemente, enfraquecendo o movimento estudantil, que até o momento se beneficiara com a força das paralisações.

Apesar de o resultado das negociações com o governo e os sindicatos ter promovido o aumento do salário mínimo, o reconhecimento das seções sindicais nas empresas, com a proteção dos delegados nomeados e ter se comprometido com a liberdade de expressão na empresa e a diminuição da jornada de trabalho, muitos grevistas prolongaram as paralisações até meados de junho, quando então o trabalho fora retomado novamente (THIOLLENT, 1998, p. 67).

Por outro lado, aliado à uma repulsa sentida em relação às hierarquias familiar e de gênero - o movimento feminista ganha força a cada dia -, a sensação de enfraquecimento da representação política frente a partidos ou outros tipos de organizações, como a militância política e sindical, vinham sendo progressivamente sendo expressadas, alterando, inclusive, a própria noção de militância, que passa a entrar em declínio especialmente a partir de 1970 (THIOLLENT, 1998, p. 86).

Como alternativa ao sistema hierárquico e autoritário denunciados por estes movimentos, portanto, o Maio de 1968 será marcado pela herança anarquista da autogestão como uma concepção construída em torno de um modo de vida e um olhar diferentes, independente das doutrinas e hierarquias estabelecidas.

Dessa forma, entre o meio estudantil, o clima pós-1968 esteve presenciado por "uma forma de 'alergia' aos fatos de autoridade", trazendo à tona a negação de qualquer forma de liderança (THIOLLENT, 1998, p. 93).

A empreitada do novo modelo econômico adotado nos países europeus e, progressivamente, em outros países do mundo ocidental, também entrava no rol das denúncias realizadas frente às doutrinas que os movimentos estudantis buscavam suplantar, basta lembrar que, nesse momento, a categoria dos estudantes teria de enfrentar o crescimento contínuo da margem de desempregados, o aumento dos impostos e, mais tarde, o aumento das previdências. 
Entretanto, a crítica feita em relação aos impactos do capitalismo industrial e que daria os primeiros passos no cenário do Maio de 1968, terá seu desenvolvimento mais contundente nos posteriores movimentos ecológicos ou entre os partidos verdes (THIOLLENT, 1998, p. 92).

Dado o forte amadurecimento dos movimentos ambientalistas, a partir dos anos 70 e 80, em 2001, já na virada do milênio, este será um dos temas a que as edições do Fórum Social Mundial irão gravitar.

Para compreender melhor o cenário em que o Fórum Social Mundial estava se inserindo, seria mais proveitoso analisar o contexto dos movimentos sociais entre os anos 1980-1990.

Como aponta Maria da Glória Ghon, entre a discussão tecida em torno dos paradigmas norte-americano e europeu sobre o significado dos movimentos sociais, em 1980, do lado dos EUA será observada a expressão de "meras estratégias políticas para a obtenção de bens", por sua vez "baseadas em lógicas racionais que consideram custos e benefícios" (GHON, 2014, p. 284); ao lado do significado europeu. Uma de suas abordagens estará voltada à preocupação para a construção de identidades. Nesse sentido, ambos estavam voltados para a expressão da identidade dos novos atores políticos que começavam a se formar.

No caso brasileiro, a ênfase repousava no aspecto das mudanças socioculturais ou nas transformações políticas, os quais, por sua vez, não diziam respeito à intenção estratégica norte-americana, mas sim, a estratégias voltadas para a ocupação do poder "e não estratégias mercadológicas, para se obter recursos econômicos junto aos poderes públicos (GHON, 2014, p. 284).

Em sua particularidade, os movimentos sociais brasileiros dos anos 1980 se constituíram no enfrentamento com o regime militar e pelo pressionamento das "Diretas Já", trazendo à tona a busca para suprir a lacuna do desemprego e instituir a mudança do regime político, com a instauração de uma nova Constituinte.

A partir dos anos 1990, ainda no caso brasileiro, uma das características dos movimentos sociais nesse período irá se desenvolver ao redor de problemáticas sociais 
"estruturadas segundo as regras do capitalismo selvagem, como a questão rural, no movimento dos sem-terra" (GHON, 2014, p. 322).

Por outro lado, outra parcela dos movimentos sociais brasileiros será caracterizada pela expressão das mesmas posturas, táticas, estratégias e práticas das duas décadas anteriores, como as greves dos professores do ensino secundário e as mobilizações das associações de moradores. No contexto brasileiro, portanto:

[...] não se trata apenas da reconstrução do regime político, da retomada da democracia e do fim do regime militar. Trata-se da reconstrução ou construção de valores democráticos, de novos rumos para a cultura do país, do preenchimento de vazios na condução da luta pela redemocratização, constituindo-se como agentes interlocutores que dialogam diretamente com a população e com o Estado (GHON, 2014 pp. 322-323).

Da constatação destas últimas características dos movimentos sociais no Brasil, a partir dos anos 1990, podemos abstrair que a tendência em assumir o papel de interlocutores entre a população e o Estado estará direcionado, cada vez mais, ao embate de provocar os questionamentos e elaborar as reivindicações pertinentes à estruturação dos princípios da nova democracia recém conquistada.

Entretanto, as circunstâncias que, no contexto brasileiro, em menos de uma década colocariam em voga as denúncias em torno da corrupção da classe política e, contemporaneamente, circulariam a sensação de ressentimento das populações de classe média e baixa diante do descumprimento das garantias de direitos, por sua vez elencados pela Constituinte, terminaram por inserir os movimentos sociais numa conjuntura comum com outros contextos, onde tanto o descrédito em relação à representatividade do povo pelo Estado, quanto a crítica em torno da filiação da governança guiada pelo lucro entram em debate.

Nessa conjuntura, a primeira realização do Fórum Social Mundial, em janeiro de 2001, na cidade de Porto Alegre, no Brasil, fora realizada entre protestos e mobilizações “contra um neoliberalismo que se pretendia triunfante", e que já vinham acontecendo e se multiplicando nos últimos anos, mundialmente (FERREIRA, 2005, p. 15).

Estes protestos e mobilizações já vinham conquistando seu espaço desde que o Levante Zapatista ocorrido na cidade Chiapas, no México, impulsionara uma contundente oposição à aprovação do Tratado Norte-Americano de Livre Comércio (NAFTA), em janeiro 
de 1994, sob a liderança do Exército Zapatista de Libertação Nacional e articulada em defesa dos direitos dos povos indígenas e de baixa renda mexicana.

Já perto da virada do milênio, em 30 de novembro de 1999, a cidade de Seattle, situada no Estado de Washington (EUA), se fez ouvir com uma manifestação numerosa em oposição a reunião da Organização Mundial do Comércio (OMC) $)^{2}$.

Entre suas reivindicações estavam articulados o repúdio do incentivo ao avanço de políticas neoliberais que ameaçavam ferir ainda mais os direitos humanos, as políticas de saúde, a educação e distribuição de renda. Ao lado dos ambientalistas havia o comprometimento de tentar barrar as negociações a serem realizadas na reunião da OMC, denunciando as ameaças envolvidas nas políticas desenvolvimentistas sobre a sustentabilidade ambiental. Enfim, grupos de sindicalistas reforçavam a luta pela manutenção dos direitos trabalhistas.

A novidade entre as mobilizações desse dia foi a proeminência de grupos de anarquistas alinhados pela rejeição à política de especulação financeira do modelo econômico vigente nas negociações assumidas pelos países envolvidos na reunião da OMC, introduzindo a execução de diferentes metodologias de ação, num ativismo elaborado em torno do confronto direto e da destruição de propriedades corporativas.

Confluindo no confronto com os efeitos negativos da globalização econômica, consolidados nos acordos econômicos internacionais como as reuniões anuais do Fórum Econômico Mundial, em Davos, na Suíça, o Fórum Social Mundial foi pensado para se contrapor ao "instrumental ideológico que visava impor universalmente o domínio absoluto da economia e do mercado sobre os rumos políticos, sociais e culturais do mundo globalizado pós derrocada soviética" (FERREIRA, 2000, p. 250). E, portanto, o Fórum Social Mundial foi elaborado como "uma operação de contracomunicação ao Fórum Econômico de Davos" (FERREIRA, 2005, p. 19).

Riqueza e democracia foram os dois grandes temas do Fórum. Daquela debateu-se sua formação, concentração e distribuição, ao lado das candentes questões do emprego, meio ambiente e a ausência de controles do capital financeiro. Da democracia discutiram-se especialmente os limites ou quase a

2 Estima-se que neste dia estiveram presentes cerca de 40 mil a 100 mil manifestantes. Fonte: BBC Brasil. Disponível em: <http://www.bbc.com/portuguese/economia/020125_fecprothistorico1.shtml>. Acesso em: 22 set. 2016. 
impotência dos Estados nacionais em face da ampla liberdade operacional do capital financeiro e o peso de órgãos multilaterais como o FMI (SGUISSARDI, 2001, p. 292 - Grifo do autor).

Partindo deste debate, o Fórum Social Mundial esteve a todo momento voltado para a elaboração de alternativas que fossem capazes de levar adiante a busca concreta de respostas aos desafios de construção de "um outro mundo"”, colocando em prática uma economia "a serviço do ser humano e não o inverso" (FERREIRA, 2000, p. 2).

A repercussão da primeira edição do Fórum Social Mundial permitiu que seus organizadores programassem novas edições, considerando a elaboração de uma "carta de princípios" que fosse capaz de assegurar a continuidade do êxito do evento nas próximas edições.

No conteúdo da Carta encontram-se elencadas, entre outros, um grupo de diretrizes redigidas para reafirmar os objetivos e as principais opções organizativas adotadas na primeira edição.

Outra série de elementos estão dispostos na Carta para fortalecer o consenso de que o Fórum Social Mundial fosse organizado, de modo permanente, como um espaço aberto, reunido em torno dos diferentes tipos de demandas, onde qualquer movimento social ou entidade da sociedade civil que carregue como mote a construção de um "outro mundo possível", tenha a possibilidade de participar com suas propostas.

Para tanto, o posicionamento dos organizadores das posteriores edições do Fórum esteve alinhado ao comprometimento de promover que o convite às articulações e discussões fossem realizados de forma não-diretiva e facilitadora, porém de maneira que fossem apresentadas e intercambiadas iniciativas objetivadas pela superação da lógica da especulação financeira globalizada.

Desse modo, o modelo de organização proposto pelo Fórum Social Mundial acabou por propiciar às edições do evento o desenvolvimento de um ativismo voltado para "uma cultura política baseada na horizontalidade e na não-diretividade", no qual os "chefes" e os “comandos" estão ausentes, "com a garantia da absoluta autonomia de cada entidade, movimento ou pessoa" (FERREIRA, 2005, p. 78). 
Á medida que um número cada vez maior de movimentos sociais e entidades civis engrossavam os espaços de debate das edições do Fórum Social Mundial, em aliança com outras organizações de outros países, seus organizadores resolveram instituir o Comitê Internacional do Fórum, estabelecido para procurar garantir o apoio e a continuidade da iniciativa do evento em escala global.

Atualmente, no ano de 2016 duas edições do Fórum Social Mundial tiveram lugar em Montrèal, no Canadá e em São Paulo, no Brasil, este último particularmente articulado em torno da temática da migração.

Os temas que passarão a ter lugar comum nas edições do Fórum Social Mundial podem ser encontrados no programa disponibilizado pela edição de Montreal $^{3}$. Ao todo, são veiculados treze temas entrelaçados: 1) Alternativas econômicas, sociais e solidárias frente à crise capitalista; 2) Democratização do conhecimento e o direito à comunicação; 3) Cultura de paz e a luta por justiça e pela desmilitarização; 4) Descolonização e autodeterminação dos povos; 5) Defesa pelos direitos da natureza e justiça ambiental; 6) Luta global e solidariedade internacional; 7) Direitos humanos e sociais, dignidade e lutas contra as desigualdades; 8) Lutas contra o racismo, a xenofobia, o patriarcado e o fundamentalismo; 9) Luta contra a ditadura financeira e pela partilha dos recursos; 10) Migração e cidadania sem fronteiras; 11) Democracia, movimentos sociais e cidadãos; 12) Trabalhadores frente ao neoliberalismo; e 13) Expressões culturais, artísticas e filosóficas para um outro mundo possível

Entre os movimentos que compuseram os protestos observados entre os anos de 2008-2013, muitos dos itens elencados como temas nas edições do fórum Social Mundial estarão dispostos numa conjuntura de resistências e rupturas de setores específicos com as classes políticas e econômicas vigentes no período.

Se por um lado, a condução guiada pelo Fundo Monetário Internacional (FMI) e pelo Banco Mundial na implementação de uma postura econômica baseada no livre mercado global resultou na busca de revitalizar o modelo econômico capitalista, a partir dos anos 1970, como fizemos notar, o trajeto de seu programa será continuamente marcado pelo abrupto aumento das desigualdades e pela potencialização da injustiça social.

\footnotetext{
3 Para a íntegra do documento, acessar: <https://fsm2016.org/wp-content/uploads/2016/07/F_S_M_2016programme_FINAL_web-B-1.pdf>.
} 
Com a crise financeira de 2008, a situação a que se encontrava os limites de acesso à garantia de direitos, por sua vez alicerçados nos princípios do Estado Democrático de Direito, deu fôlego para que uma onda de protestos invadisse o cenário mundial e trouxesse a denúncia dos excessos praticados pela especulação financeira e reclamasse a conquista ou a devolução dos direitos que, cada vez mais, não encontra na classe política a expressão de sua proteção e garantia.

Entre as características que envolviam estes movimentos no desenvolvimento de um novo modo de fazer política, Manuel Castells ${ }^{4}$ resgata a circulação de princípios como a autonomia, a independência, a horizontalidade e a solidariedade, os quais, como observado, tendem a se assemelhar às práticas e metodologias introduzidas pelos por movimentos como o Maio de 1968 e as organizações das edições do Fórum Social Mundial.

Entretanto, a novidade ainda mais marcante entre os movimentos da atualidade será o recurso ao ciberativismo, como instrumento funcional para a reconfiguração do ativismo político.

Dessa forma, através do recurso à instrumentalização do ciberativismo estes movimentos expressam, a cada dia, um aumento considerável de insatisfação frente aos meios de reivindicação tradicionais, como os estruturados na eleição da classe política ou mesmo pela representação das instituições midiáticas, vista muitas vezes como defensora do status quo e desmobilizadora dos movimentos sociais.

Portanto, as alternativas propostas pelos movimentos sociais da atualidade passam a expressar, gradativamente, um protagonismo político mais centralizado nos meios nãotradicionais de reivindicação, num híbrido entre a solidariedade das redes sociais e tomada das ruas, mas, principalmente, voltado para a denúncia dos excessos da especulação financeira no modelo capitalista e para o repúdio das classes políticas vigentes na organização do Estado contemporâneo.

\section{CONCLUSÃO}

${ }^{4}$ Cf. CASTELLS, M. Redes de indignação e esperança: movimentos sociais na era da internet. Tradução Carlos Alberto Medeiros. Rio de Janeiro: Zahar, 2013. 
Como vimos, antes do advento da onda de protestos resultante do enfrentamento com o modelo econômico e político vigentes no contexto da crise financeira de 2008, as propostas veiculadas em torno da implantação de um novo modelo de participação política estiveram alinhadas a movimentos como os acontecidos em Maio de 1968, como também os organizados pelas diferentes edições do Fórum Social Mundial.

Se no primeiro caso, as mudanças de paradigmas estavam direcionadas à contestação das autoridades e das hierarquias institucionais como a família e o próprio conceito de militância, por sua vez, o Fórum Social Mundial será criado para se contrapor ao instrumental ideológico elaborado para impor universalmente o domínio absoluto da economia e do mercado sobre os rumos da política e das sociedades como um todo.

O percurso da especificidade brasileira, por outro lado, num ambiente ainda pouco familiarizado com a vivência democrática, será marcado, a partir de 2001, com o Fórum Social Mundial, mas especialmente a partir da crise de 2008, pelo clima de denúncia dos excessos praticados pela especulação financeira e da falta de representabilidade diante do poder público.

Portanto, se alguns autores apontam para o desgaste da esquerda política entre as sociedades ocidentais, devida a uma perda crescente do ideal revolucionário, por outro lado, o histórico destes movimentos, em escala global, propiciará um debate ainda em curso sobre as alternativas possíveis em relação aos modelos tradicionais de participação política.

\section{REFERÊNCIAS BIBLIOGRÁFICAS}

BACOCCINA, D. Movimento anti-globalização ganha voz a partir de Seattle. $B B C$ Brasil. São Paulo, 28 jan. 2002. Disponível em: <http://www.bbc.com/portuguese/economia/020125_fecprothistorico1.shtml>.

CASTELLS, M. Redes de indignação e esperança: movimentos sociais na era da internet. Tradução de Carlos Alberto Medeiros. Rio de Janeiro: Zahar, 2013. 
FERREIRA, C. W. O desafio do Fórum Social Mundial: um modo de ver. São Paulo: Loyola, 2005.

GHON, M. da G. Teorias dos movimentos sociais: paradigmas clássicos e contemporâneos. 11. ed. São Paulo: Loyola, 2014.

HOBSBAWM, E. J. Era dos extremos: o breve século XX: 1914-1991. Tradução de Marcos Santarrita. São Paulo: Companhia das Letras, 1995.

JUDT, T. O mal ronda a terra: um tratado sobre as insatisfações do presente. Tradução de Celso Nogueira. Rio de Janeiro: Objetiva, 2011.

MORIN, E. A via para o futuro da humanidade. Tradução de Edgar de Assis Carvalho e Mariza Perassi Bosco. Rio de Janeiro: Bertrand Brasil, 2013.

THIOLLENT, Michel. Maio de 1968 em Paris: testemunho de um estudante. Tempo Social, São Paulo, v. 10, n. 2, p. 63-100, dec. 1998. ISSN 1809-4554. Disponível em: <http://www.revistas.usp.br/ts/article/view/86781>. Acesso em: 12 set. 2016.

SGUISSARDI, V. Fórum Social Mundial: um outro mundo é possível. Educação \& Sociedade, ano XXII, $\mathrm{n}^{\circ} 75$, Agosto/2001. 